\title{
Adverse Effects from the Imposition of Social Restrictions in Greece: the Indirect Effect of COVID-19-Related Fear on Alcohol Consumption Through Loneliness
}

\author{
Iraklis Grigoropoulos ${ }^{1,2} \cdot$ Konstantinos Christos Daoultzis ${ }^{2}$
}

Accepted: 16 February 2022 / Published online: 1 March 2022

(C) Associação Brasileira de Psicologia 2022

\begin{abstract}
Quarantine and social distancing are crucial factors in blocking the consequences of COVID-19 but also can lead to higher levels of loneliness and social isolation. Therefore, any advantages of mandatory quarantine have to be weighed against any negative impact on physical and mental well-being. This study aimed to examine the relationship between COVID-19-related fear and alcohol use during the lockdown period and loneliness as a mediating factor increasing the impact of COVID-19-related fear on alcohol use. A sample of 279 young adults completed self-reported questionnaires on COVID-19-related fear, loneliness, and substance use. This exploratory cross-sectional research was administered from 11 until December 18, 2020. The results showed that loneliness during lockdown mode may exacerbate the emotional burden caused by COVID-19-related fear leading to increased alcohol consumption as a coping mechanism against unsatisfactory living conditions. This study's results reflect the need for societal groups, as well as health care services to remain specifically considerate to the needs of individuals who report high levels of COVID-19-related fear and loneliness.
\end{abstract}

Keywords Social distancing · Social restriction · Loneliness · COVID-19-related fear $\cdot$ Substance use

There is a growing interest in the possible mental and physical health consequences of mandatory quarantine measures that are enforced as the most useful preventive strategies for the expansion of COVID-19 (Grigoropoulos, 2022; Skapinakis et al.,

Iraklis Grigoropoulos griraklis@gmail.com

Konstantinos Christos Daoultzis constantinos.daoultzis@gmail.com

1 Department of Psychology, Panteion University, Athens, Greece

2 Department of Psychology, Panteion University of Social and Political Sciences, Athens, Greece 
2020; Yeung \& Fung, 2007). However, the consequences of compulsory quarantine and social distancing, even though social distancing does not necessarily lead to social isolation, may have significant negative mental health effects while at the same time represent risk factors for higher general morbidity (Armitage \& Nellums, 2020). According to Rossi et al. (2020), elevated levels of loneliness caused by the pandemic quarantine can intensify negative psychological reactions to COVID-19. Previous research findings show that self-restraint, loss of everyday routines, and loneliness because of the loss of someone's social network may cause stress and a sense of isolation which in some cases might have dramatic results (Ahorsu et al., 2020; Braunack-Mayer et al., 2013; DiGiovanni et al., 2004). Separation from family and loved ones, loss of freedom, and boredom can trigger anxiety reactions implying pandemic quarantine as a purely unpleasant experience that can have a profound influence on mental health (Brooks et al., 2020). Therefore, any advantages of the mandatory quarantine have to be weighed against any negative mental health impact (Rubin \& Wessely, 2020). Overall, even though social distance and quarantine isolation are crucial prophylactic measures, these strategies along with the COVID-19 outbreak and its social and psychological risks can intensify substance abuse in a potentially catastrophic cycle (Ornell et al., 2020).

\section{Drinking to Cope with Negative Affective States}

The increased levels of uncertainty, stress, and fear due to the COVID-19 outbreak along with disrupted routines may have made it more likely for some people to progress into heavier drinking habits. When people are more stressed, they may rely more on alcohol and drug use (APA, 2021). According to the motivational model of alcohol use (Cox \& Klinger, 1988), there are four different drinking motives, namely, enhancement motive (drinking to enhance positive experience or emotions), social motive (drinking to obtain positive social rewards), coping motive (drinking to cope with negative affect), and conformity motive (drinking to avoid social rejection) (Tartaglia \& Bergagna, 2020). Adult people highly pressured and/or dissatisfied with their living conditions are more likely to drink to cope with negative emotions (Pavot \& Diener, 1993). However, this way of coping is associated with alcohol abuse and alcohol-related problems (Labouvie \& Bates, 2002).

According to Folkman and Lazarus (1988, p. 310), "coping consists of cognitive and behavioral efforts to manage specific external and/or internal demands that are appraised as taxing or exceeding the resource of the person." Hence, if possible threatening stressors are present, people use different forms of coping strategies to avoid the experience of negative affective states. Coping can be considered as a psychological response to perceptions of threat to prevent and/or reduce it (Skapinakis et al., 2020). Thus, alcohol may be used to avoid the experience of depression, fear, or anxiety as some people may use the drinking coping motive to overcome life stressors ("non-functional" coping strategy) (Abu-Raiya et al., 2011; Tartaglia \& Bergagna, 2020; Rona et al., 2007).

On the other side, the use of "functional" coping strategies is related to better outcomes as regards facing different kinds of stressors (for example, social stress 
or cancer) (Skapinakis et al., 2020). Research also underlines the adaptive, "functional" role of fear suggesting that the perceived fear against COVID-19 operates as a prophylactic factor that may result in better adjustment against the pandemic outbreak and may also predict compliance with preventive measures. For example, in the case of COVID-19-related fear, it may act as a stimulation factor to engage in behaviors that facilitate COVID-19 prevention (Harper et al., 2020).

However, research data also report that people are likely to resort to the disproportionate use of drugs or alcohol while seeking to manage self-isolation-associated stress. As Carver (1997) suggests, non-functional coping strategies (such as drinking to cope with negative affect) are effective in coping with self-isolation but they may result in the continuation of the psychological distress (Barlow et al., 2014). Therefore, the enactment of a set of non-functional or functional coping strategies may be related to worse or better mental and physical health outcomes when faced with health-related traumatic events (Skapinakis et al., 2020).

\section{Loneliness and Social Isolation}

Jeste et al. (2020) report that loneliness and social isolation were described as a worldwide "behavioral epidemic" even before the COVID-19 outbreak. However, the pandemic outbreak exacerbated their consequences with the imposed restrictions.

The World Health Organization has already expressed its concern as regards the pandemic outbreak health and psychological consequences and in particular the increase in loneliness, anxiety, insomnia, and harmful alcohol and drug use (Kumar \& Nayar, 2021). Even though social distancing does not necessarily lead to social isolation, they seem to co-occur. According to Hwang et al. (2020), the concept of loneliness refers to the subjective feeling of being alone whereas social isolation refers to an individual's social interaction patterns. Loneliness represents the perceived lack of social connections (Hawkley \& Cacioppo, 2010; Lee \& Goldstein, 2015; Ni et al., 2015) which may be felt regardless of the physical company and/or proximity of others (such as friends or spouses).

According to Rokach and Shaked (2013), loneliness is a subjective experience influenced by one's personality, experiences, relationships, and situational variables. Loneliness is related to a desire for more and better social relationships and can be predicted by the absence of meaningful interactions, lack of social support, lack of balance in everyday activities, and worsen mental and physical health (Cigna, 2020). In turn, researchers acknowledged loneliness not only as a psychological problem but as a health problem too. Hawkley and Cacioppo (2007) noted that loneliness can result in health impairing behaviors. Specifically, Hawkley and Cacioppo (2003) argued that "loneliness might also increase behaviors such as smoking or alcohol use, behaviors that contribute to health risk" (p. 100). Behaviors that received a specific focus of attention are alcohol and/or other substance use (Hawkley \& Cacioppo, 2003, 2007).

On the other side, social isolation is also related to negative practices such as alcohol consumption, smoking, and decreased physical activity (Kobayashi \& 
Steptoe, 2018). Overall, empirical evidence emphasizes the profound effect of loneliness and social isolation on physical and emotional well-being even though they are not the same (Hwang et al., 2020).

\section{The Current Study}

During the second wave of the COVID-19 pandemic, Greece has taken all the appropriate precautions to reduce its spread in the country. Multiple restrictions have been imposed on public movement, including travel limitations and the compulsory closure of schools. Subsequently, all aspects of everyday life were affected in Greece. People were required to stay at home and avoid social interaction to prevent being infected. Greek research findings report that being older and female were associated with higher COVID-19-related fear (Parlapani et al., 2020). According to Skapinakis et al. (2020), people in Greece used mainly functional coping strategies to adjust to stress caused by the epidemic while their behavioral pattern may affect the possible negative consequences of the epidemic.

Greek research data during the pandemic outbreak show a significant decrease in alcohol consumption. Possible explanations for this decrease were the limited alcohol availability and socialization along with participants' possible concern for their health (Panagiotidis et al., 2020). However, an important $13.6 \%$ also noted that they were drinking to cope with anxiety symptoms or depressed mood (Panagiotidis et al., 2020). Thus, the pandemic outbreak may have contributed to an increase in alcohol use to those who may lack the ability to cope with increased emotional burden and use functional coping strategies.

Pandemic-related strains, associated economic stress, loneliness, and anxiety about the virus may increase unhealthy behaviors including drinking more and taking drugs (APA, 2021). Considering that during the pandemic outbreak and lockdown mode international studies show an increase in alcohol consumption (Kumar \& Nayar, 2021), there is reason to believe that increased COVID-19-related fear may be associated with higher levels of alcohol use especially for those who use alcohol to cope with negative affective states.

Taking into account that there is evidence to support the drinking to cope with negative affect model (use of alcohol as a way to cope with negative emotions and stressors) (Chilcoat \& Menard, 2003), this study aimed to examine the relationship between COVID-19-related fear and alcohol use during the lockdown period and loneliness as a mediating factor increasing the impact of COVID-19-related fear on alcohol use.

\section{Method}

\section{Data Collection and Participants}

The current exploratory cross-sectional study was administrated from 11 until December 18, 2020, and used convenience sampling due to COVID-19 lockdown 
mode. The questionnaire (in Google forms) was circulated through social media (e.g., Facebook). Potential participants of the Greek general population were called to participate voluntarily and individually answer the questionnaire. While accessing the survey, they were informed about the nature of the study. Participants consented to participate in the study by clicking the consent checkbox. Willingness to participate and being an adult were the inclusion criteria of this study. This study included 44 (15.8\%) men, 228 (81.7\%) women, and 7 (2.5\%) individuals that stated "other" in the blank line regarding gender. The mean age was $23.32(S D=7.66)$. Most of the participants lived in the area of Thessaloniki, Greece $(61.3 \%$ ), and were bachelor students $(221-79.2 \%)$. This study adhered to all ethical guidelines of the institution to which the researchers belong and was in agreement with the Declaration of Helsinki ethical principles (World Medical Association 2001).

\section{Measures}

This study involved the following:

1. Basic demographic questions (age, gender, educational level, place of residence).

2. Drinking to cope with negative affect. Respondents were asked to indicate, using a 5 -point scale $(0=$ not at all to $4=$ nearly every day over the last 2 weeks $)$, how frequently they engaged in drinking to cope with negative affect behaviors during pandemic quarantine. This item shows participants' engagement in maladaptive coping with the coronavirus. Alcohol use was estimated by the item, "I used alcohol to help me get through the fear and/or anxiety caused by the coronavirus" (see Lee, 2020).

3. Psychometric scales evaluating COVID-19-related fear and loneliness, namely:

(a) The fear of COVID-19 scale (FCV-19S). A one-dimensional scale for evaluating COVID-19-related fear. The FCV-19S is a self-report measure (e.g., item 1, "I am most afraid of coronavirus-19") based on a 5-point scale $(1=$ strongly disagree to $5=$ strongly agree). Total scores range between 7 and 35. Higher scores indicate greater fear of COVID-19. The original scale reported very good internal consistency $(a=0.82)$ (Ahorsu et al., 2020).

(b) This study made use of the Greek version of FCV-19S (see Tsipropoulou et al., 2020). Total scores of 16.5 or higher indicated an important predictive power for anxiety, health anxiety, and posttraumatic stress symptoms (Nikopoulou et al., 2020; Tsipropoulou et al., 2020). In the present study, Cronbach's alpha was found $a=0.84$.

(c) Participants' current level of loneliness was measured by the UCLA Loneliness Scale. This scale is a 20 -item self-report measure in which participants rate each item on a 4 -point scale ( $1=$ never to $4=$ often) (e.g., How often do you feel left out? How often do you feel part of a group of friends?). This study made use of the Greek version of the UCLA Loneliness Scale (Maragkou, 2015). The UCLA Loneliness Scale was completed by participants as a measure of their current level of loneliness. Loneliness scores 
are calculated by adding all items (after reversing the appropriate items). Total scores vary from 20 to 80 , with higher scores indicating higher levels of loneliness. In the present study, Cronbach's alpha was found $a=0.91$.

Data screening techniques were applied before the main statistical analysis. The normal range for skewness and kurtosis are considered to be between +2 and -2 for normal distribution according to the criteria by George and Mallery (2010) and that assumption is satisfied, as the values for skewness were found between 0.17 and 1.62 and for kurtosis between -0.87 and 2.51. Also, the Mahalanobis distance test identified no multivariate outliers.

\section{Results}

For investigating any potential associations between the study's variables and demographic characteristics, a one-way ANOVA was conducted and showed that COVID-19-related fear is differentiated between men, women, and those who stated "other" gender $\left(F_{2,276}=3.806 ; p<0.05, \eta_{p}{ }^{2}=0.03\right)$. Bonferroni post hoc test reported a significant difference of the mean COVID-19-related fear value between LGBTQ $+(M=19.00, S D=6.98)$ and men $(M=13.55, S D=4.08)$ $(p<0.05)$. No statistically detected difference was found between the two groups concerning loneliness. Further, age and COVID-19-related fear were significantly correlated, $r_{274}=0.129, p<0.05$, while age was not found correlated with loneliness, $r_{274}=-0.11(p=0.68)$.

To investigate the relationship between the variables of the research, the Pearson correlation analysis was applied, after the statistical assumptions were checked. Loneliness was found to be positively correlated with fear of COVID $\left(r_{276}<0.27\right.$, $p<0.001)$ and alcohol use $\left(r_{276}<0.17, p=0.005\right)$, while COVID-19-related fear was found also to be positively correlated with alcohol use $\left(r_{276}<0.12, p=0.038\right)$.

A simple mediation model was used to examine the effect of COVID-19-related fear on alcohol use through the mediation of the feeling of loneliness due to COVID-19. Model 4 of PROCESS (one mediation variable) was used to calculate both models. The results of the models are reported in Table 1 and Graph 1.

According to the first model, the effect of COVID-19-related fear on alcohol use was indeed mediated by feelings of loneliness. As Table 1 and Graph 1 report, the standardized coefficient between COVID-19-related fear and loneliness was statistically significant $(p=0.031)$, as was the standardized coefficient between loneliness and alcohol use $(p=0.009)$. The direct effect of fear for COVID on alcohol use was found to be not statistically significant $(p=0.093)$, enhancing the mediation role of loneliness and further supporting the mediation model. Finally, the overall model was found to have a statistically significant standardized effect factor $(p=0.045)$. Based on the above, it turns out that higher levels of COVID19-related fear lead to higher levels of loneliness and, in turn, a greater risk for alcohol use can be predicted. 
Table 1 Indirect and total effects (simple mediation model on alcohol and substance abuse)

\begin{tabular}{|c|c|c|c|c|c|c|c|c|}
\hline \multirow[t]{2}{*}{ Type } & \multirow[t]{2}{*}{ Effect } & \multirow[t]{2}{*}{ Estimate } & \multirow[t]{2}{*}{ SE } & \multicolumn{2}{|l|}{$95 \% \mathrm{CI}$} & \multirow[t]{2}{*}{$\beta$} & \multirow[t]{2}{*}{$z$} & \multirow[t]{2}{*}{$p$} \\
\hline & & & & Lower & Upper & & & \\
\hline Indirect & $\begin{array}{l}\text { Fear of COVID } \rightarrow \text { loneli- } \\
\text { ness } \rightarrow \text { alcohol use }\end{array}$ & 0.03 & 0.02 & -0.00 & 0.06 & 0.02 & 1.67 & 0.095 \\
\hline \multirow[t]{2}{*}{ Component } & Fear of COVID $\rightarrow$ loneliness & 3.07 & 1.42 & 0.28 & 5.86 & 0.13 & 2.16 & 0.031 \\
\hline & Loneliness $\rightarrow$ alcohol use & 0.01 & 0.00 & 0.00 & 0.02 & 0.16 & 2.62 & 0.009 \\
\hline Direct & Fear of COVID $\rightarrow$ alcohol use & 0.14 & 0.08 & -0.02 & 0.30 & 0.10 & 1.68 & 0.093 \\
\hline Total & Fear of COVID $\rightarrow$ alcohol use & 0.17 & 0.08 & 0.00 & 0.33 & 0.12 & 2.00 & 0.045 \\
\hline
\end{tabular}

Confidence intervals computed with method: standard (Delta method). Betas are completely standardized effect sizes

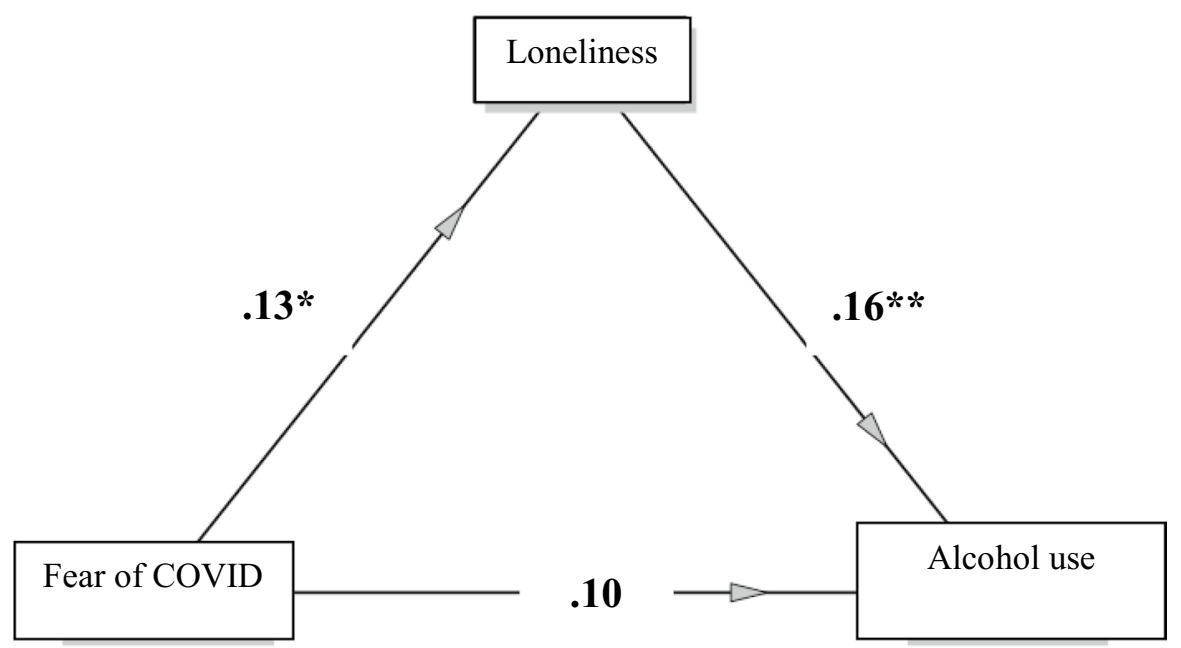

Graph 1 The standardized coefficient between COVID-19-related fear and loneliness was statistically significant, as was the standardized coefficient between loneliness and alcohol use

\section{Discussion}

Since the COVID-19 pandemic, the world is facing physical and mental health challenges. Coronavirus disease outbreak influences life worldwide. Furthermore, the COVID-19 outbreak has had a significant impact on loneliness regarding the general population (Li \& Wang, 2020). Different countries enacted different measures to prevent the outbreak; however, the most used measures across countries were lockdown, social isolation, and confinement (Grigoropoulos \& Tekelidou, 2021; Lin, 2020; Pakpour et al., 2020). Even though social restrictions are often an unpleasant situation on many occasions, they were deemed necessary. Most governments not only suggested such behaviors but have even established penalization against offenders. However, the loss of freedom, boredom, and on occasion separation from loved ones can have a dramatic impact on people's lives 
(Barbisch et al., 2015; Brooks et al., 2020). Recent research data report the longterm effects of social distancing if the experience is negative. These data also emphasize that depriving people of their liberty for the wider public good is often controversial and may intensify frustration and demoralization (Hwang et al., 2020).

Previous trauma situations already show that people may react in different ways to overwhelming experiences. An increase in alcohol drinking may be one of the possible responses (De Goeij et al., 2015). Research findings already underline alcohol misuse during the COVID-19 outbreak (Koob et al., 2020; Rehm et al., 2020). Under the current extreme situations, COVID-19-related fear may be one of the most important underlying factors that could lead to an increased risk as regards physical and emotional well-being (Kumar \& Nayar, 2021).

This study aimed to examine the relationship between COVID-19-related fear and alcohol use during the lockdown period and loneliness as a mediating factor increasing the impact of COVID-19-related fear on alcohol use. The results show that COVID-19-related fear was positively associated with loneliness and alcohol use. However, there were no potential direct effects of COVID-19-related fear on increased levels of alcohol use. There was, though, a constant indirect effect of COVID-19-related fear on substance use, through increased levels of loneliness.

Therefore, this study's results show that loneliness may be an important mediating factor connecting COVID-19-related fear with increased alcohol use. Loneliness during lockdown mode may exacerbate the emotional burden caused by COVID19-related fear leading to increased alcohol consumption as a coping mechanism against unsatisfactory living conditions.

In this way, this study's findings underscore the possible impact of loneliness on people who may exhibit high levels of COVID-19-related fear, by intensifying their tendency to become involved in health risk behaviors such as increased alcohol. These findings coincide with other COVID-19 research data reporting higher levels of alcohol and drug consumption during pandemic quarantine (Koob et al., 2020; Rehm et al., 2020). As Struk et al. (2020) suggest, having nothing in particular to do and feeling bored may also result in negative consequences which include problems with alcohol in youth and older adults (Biolcati et al., 2017; Kuerbis et al., 2018).

In all, in this study, COVID-19-related fear did not have any direct effect on substance use. However, it did have significant indirect effects, through increased levels of loneliness. Prior research data highlight the fact that loneliness constitutes a significant threat to physical health. One main mechanism through which loneliness has been reported to affect health is through health impairing behaviors (Hawkley \& Cacioppo, 2003, 2007). Alcohol use as a mechanism to endure the pandemic burden is discouraged as it can prove unsafe due to its association with alcohol-related outcomes in longitudinal studies (Holahan et al., 2001; Veenstra et al., 2007). Thus, COVID-19-related fear may be under certain circumstances (such as increased feelings of loneliness), a noted risk factor for the onset and continuation of alcohol misuse (Clay \& Parker, 2020). This can also mean that in some cases, loneliness can modify the adaptive, "functional" role of COVID19-related fear and promote unhealthy responses (Harper et al., 2020). This study's results reflect the need for community organizations, as well as health 
services, to remain particularly attentive to the needs of individuals who report high levels of COVID-19-related fear and loneliness during health crises.

Successful use of robust social restrictions and social distancing as a public health measure obliges us to minimize the negative consequences related to it.

Social interaction is crucial during this coronavirus disease outbreak. Most importantly, we should acknowledge the difference between physical and social space. Social distancing may not be viewed as social disconnection and psychological disengagement (Brooks et al., 2020; Hwang et al., 2020). Specific interventions could focus on the coping function of alcohol consumption and help develop different coping mechanisms for overcoming demanding living conditions.

\section{Limitations}

This study's exploratory cross-sectional design limited the opportunity to assess the impact of time on COVID-19-related fear. Future studies could estimate the long-term effects of COVID-19-related fear. In addition, this study lacked the quantification of the use of alcohol. Additionally, this study's convenience sampling may have restricted results impact due to a volunteer effect and the actual overrepresentation of female individuals holding a bachelor's degree. Finally, the values of the correlation coefficients indicate that the described dependencies were not highly correlated.

\section{Conclusions}

This study's findings imply loneliness as an important factor deserving further examination as regards its effect on the relationship between COVID-19-related fear and increased alcohol use. Overall, the possibility of a vicious circle's creation between COVID-19-related fear, loneliness, and alcohol misuse due to the pandemic quarantine is highlighted through this study as worthy of further examination.

Data Availability The data that support the findings of this study are available from the corresponding author upon reasonable request.

\section{Declarations}

Ethics Approval All procedures performed in studies involving human participants were in accordance with the ethical standards of the International Hellenic University research committee and with the 1964 Helsinki declaration and its later amendments or comparable ethical standards.

Consent to Participate Informed consent was obtained from all individual participants included in the study.

Competing Interests The authors declare no competing interests. 


\section{References}

Abu-Raiya, H., Pargament, K. I., \& Mahoney, A. (2011). Examining coping methods with stressful interpersonal events experienced by Muslims living in the United States following the 9/11 attacks. Psychology of Religion and Spirituality, 3(1), 1-14. https://doi.org/10.1037/a0020034

Ahorsu, D. K., Lin, C.-Y., Imani, V., Saffari, M., Griffiths, M. D., \& Pakpour, A. H. (2020). The fear of COVID-19 scale: Development and initial validation. International Journal of Mental Health and Addiction. https://doi.org/10.1007/s11469-020-00270-8

American Psychological Association. (2021). Drinking, coping, and COVID-19. https://www.apa.org/ monitor/2021/01/alcohol-covid. Accessed 28 Apr 2020.

Armitage, R., \& Nellums, L. B. (2020). COVID-19 and the consequences of isolating the elderly. The Lancet. Public Health, 5(5), e256. https://doi.org/10.1016/S2468-2667(20)30061-X

Barbisch, D., Koenig, K. L., \& Shih, F. Y. (2015). Is there a case for quarantine? Perspectives from SARS to Ebola. Disaster Medicine and Public Health Preparedness, 9(5), 547-553. https://doi. org/10.1017/dmp.2015.38

Barlow, D. H., Ellard, K. K., Sauer-Zavala, S., Bullis, J. R., \& Carl, J. R. (2014). The origins of neuroticism. Perspectives on Psychological Science : A Journal of the Association for Psychological Science, 9(5), 481-496. https://doi.org/10.1177/1745691614544528

Biolcati, R., Mancini, G., \& Trombini, E. (2017). Proneness to boredom and risk behaviors during adolescents' free time. Psychological Reports, 121(2), 303-323. https://doi.org/10.1177/00332 94117724447

Braunack-Mayer, A., Tooher, R., Collins, J. E., Street, J. M., \& Marshall, H. (2013). Understanding the school community's response to school closures during the H1N1 2009 influenza pandemic. BMC Public Health, 13, 344. https://doi.org/10.1186/1471-2458-13-344

Brooks, S. K., Webster, R. K., Smith, L. E., Woodland, L., Wessley, S., Greenberg, N., \& Rubin, J. G. (2020). The psychological impact of quarantine and how to reduce it: Rapid review of the evidence. The Lancet, 395(10227), 912-920. https://doi.org/10.1016/S0140-6736(20)30460-8

Carver, C. S. (1997). You want to measure coping but your protocol's too long: Consider the brief COPE. International Journal of Behavioral Medicine, 4(1), 92-100. https://doi.org/10.1207/ s15327558ijbm0401_6

Chilcoat, H. D., \& Menard, C. (2003). Epidemiological investigations: Comorbidity of posttraumatic stress disorder and substance use disorder. In P. Ouimette \& P. J. Brown (Eds.), Trauma and substance abuse: Causes, consequences, and treatment of comorbid disorders (pp. 9-28). American Psychological Association. https://doi.org/10.1037/10460-001

Cigna. (2020). Cigna takes action to combat the rise of loneliness and improve mental wellness in America. Cigna. https://www.multivu.com/players/English/8670451-cigna-2020-lonelinessindex/. Accessed 25 May 2020.

Clay, J. M., \& Parker, M. O. (2020). Alcohol use and misuse during the COVID-19 pandemic: A potential public health crisis? The Lancet. Public Health, 5(5), e259. https://doi.org/10.1016/ S2468-2667(20)30088-8

Cox, W. M., \& Klinger, E. (1988). A motivational model of alcohol use. Journal of Abnormal Psychology, 97, 168-180. https://doi.org/10.1037//0021-843x.97.2.168

De Goeij, M. C. M., Suhrcke, M., Toffolutti, V., van de Mheen, D., Schoenmakers, T. M., \& Kunst, A. E. (2015). How economic crises affect alcohol consumption and alcohol-related health problems: A realist systematic review. Social Science \& Medicine, 131, 131-146. https://doi.org/10.1016/j. socscimed.2015.02.025

DiGiovanni, C., Conley, J., Chiu, D., \& Zaborski, J. (2004). Factors influencing compliance with quarantine in Toronto during the 2003 SARS outbreak. Biosecurity and Bioterrorism : Biodefense Strategy, Practice, and Science, 2(4), 265-272. https://doi.org/10.1089/bsp.2004.2.265

Folkman, S., \& Lazarus, R. S. (1988). Coping as a mediator of emotion. Journal of Personality and Social Psychology, 54(3), 466-475. https://doi.org/10.1037/0022-3514.54.3.466

George, D., \& Mallery, P. (2010). SPSS for Windows step by step: A simple guide and reference 17.0 update (10th ed.). Pearson.

Grigoropoulos, I. (2022). Difficulties imposed on the parent-child relationship due to the COVID-19 pandemic. Journal of Family Issues. https://doi.org/10.1177/0192513X211067527 
Grigoropoulos, I, \& Tekelidou, M. (2021). Consequences of the parental emotional burden during the COVID-19 pandemic. Archives of Hellenic Medicine, 38(5), 651-656. Retrieved from http://mednet.gr/archives/2021-5/pdf/651.pdf. Accessed 8 Oct 2021.

Harper, C. A., Satchell, L. P., Fido, D., \& Latzman, R. D. (2020). Functional fear predicts public health compliance in the COVID-19 pandemic. International journal of mental health and addiction, 1-14. Advance online publication. https://doi.org/10.1007/s11469-020-00281-5

Hawkley, L. C., \& Cacioppo, J. T. (2003). Loneliness and pathways to disease. Brain, Behavior, and Immunity, 17(1), 98-105. https://doi.org/10.1016/s0889-1591(02)00073-9

Hawkley, L. C., \& Cacioppo, J. T. (2007). Aging and loneliness: Downhill quickly? Current Directions in Psychological Science, 16, 187-191. https://doi.org/10.1111/j.1467-8721.2007.00501.x

Hawkley, L. C., \& Cacioppo, J. T. (2010). Loneliness matters: A theoretical and empirical review of consequences and mechanisms. Annals of Behavioral Medicine, 40, 218-227. https://doi.org/10.1007/ s12160-010-9210-8

Holahan, C. J., Moos, R. H., Holahan, C. K., Cronkite, R. C., \& Randall, P. K. (2001). Drinking to cope, emotional distress and alcohol use and abuse: A ten-year model. Journal of Studies on Alcohol, 62(2), 190-198. https://doi.org/10.15288/jsa.2001.62.190

Hwang, T. J., Rabheru, K., Peisah, C., Reichman, W., \& Ikeda, M. (2020). Loneliness and social isolation during the COVID-19 pandemic. International Psychogeriatrics, 32(10), 1217-1220. https:// doi.org/10.1017/S1041610220000988

Jeste, D. V., Lee, E. E., \& Cacioppo, S. (2020). Battling the modern behavioral epidemic of loneliness. JAMA Psychiatry. https://doi.org/10.1001/jamapsychiatry.2020.0027

Kobayashi, L. C., \& Steptoe, A. (2018). Social isolation, loneliness, and health behaviors at older ages: Longitudinal cohort study. Annals of Behavioral Medicine, 52(7), 582-593. https://doi.org/10.1093/ $\mathrm{abm} / \mathrm{kax} 033$

Koob, G. F., Powell, P., \& White, A. (2020). Addiction as a coping response: Hyperkatifeia, deaths of despair, and COVID-19. American Journal of Psychiatry, 177, 1031-1037. https://doi.org/10.1176/ appi.ajp.2020.20091375

Kuerbis, A., Treloar Padovano, H., Shao, S., Houser, J., Muench, F. J., \& Morgenstern, J. (2018). Comparing daily drivers of problem drinking among older and younger adults: An electronic daily diary study using smartphones. Drug and Alcohol Dependence, 183, 240-246. https://doi.org/10.1016/j. drugalcdep.2017.11.012

Kumar, A., \& Nayar, K. R. (2021). COVID 19 and its mental health consequences. Journal of Mental Health (abingdon, England), 30(1), 1-2. https://doi.org/10.1080/09638237.2020.1757052

Labouvie, E., \& Bates, M. E. (2002). Reasons for alcohol use in young adulthood: Validation of a threedimensional measure. Journal of Studies on Alcohol, 63, 145-155. https://doi.org/10.15288/jsa. 2002.63.145

Lee, S. A. (2020). Coronavirus Anxiety Scale: A brief mental health screener for COVID-19 related anxiety. Death Studies, 44(7), 393-401. https://doi.org/10.1080/07481187.2020.1748481

Lee, C. Y. S., \& Goldstein, S. E. (2015). Loneliness, stress, and social support in young adulthood: Does source of support matter? Journal of Youth and Adolescence, 45, 568-580. https://doi.org/10.1007/ s10964-015-0395-9

Li, L. Z., \& Wang, S. (2020). Prevalence and predictors of general psychiatric disorders and loneliness during COVID-19 in the United Kingdom. Psychiatry Research, 291, 113267. https://doi.org/10. 1016/j.psychres.2020.113267

Lin, C.-Y. (2020). Social reaction toward the 2019 novel coronavirus (COVID-19). Social Health Behavior, 3, 1-2. https://doi.org/10.4103/SHB.SHB_11_20

Maragkou, E. (2015). Facebook relationship with feelings of loneliness and self-esteem [Unpublished master's thesis]. The University of Makedonia.

Ni, S., Yang, R., Zhang, Y., \& Dong, R. (2015). Effect of gratitude on loneliness of Chinese college students: Social support as a mediator. Social Behavior and Personality, 43, 559-566. https://doi.org/ 10.2224/sbp.201543.4.559

Nikopoulou, V. A., Holeva, V., Parlapani, E., Karamouzi, P., Voitsidis, P., Porfyri, G. N., Blekas, A., Papigkioti, K., Patsiala, S., \& Diakogiannis, I. (2020). Mental health screening for COVID-19: A proposed cutoff score for the Greek version of the Fear of COVID-19 Scale (FCV-19S). International Journal of Mental Health and Addiction, 1-14. https://doi.org/10.1007/s11469-020-00414-w

Ornell, F., Moura, H. F., Scherer, J. N., Pechansky, F., Kessler, F., \& von Diemen, L. (2020). The COVID19 pandemic and its impact on substance use: Implications for prevention and treatment. Psychiatry Research, 289, 113096. https://doi.org/10.1016/j.psychres.2020.113096 
Pakpour, A. H., Griffiths, M. D., Chang, K. C., Chen, Y. P., Kuo, Y. J., \& Lin, C. Y. (2020). Assessing the fear of COVID-19 among different populations: A response to Ransing et al. (2020). Brain, Behavior, and Immunity, 89, 524-525. https://doi.org/10.1016/j.bbi.2020.06.006

Panagiotidis, P., Rantis, K., Holeva, V., Parlapani, E., \& Diakogiannis, I. (2020). Changes in alcohol use habits in the general population, during the COVID-19 lockdown in Greece. Alcohol and Alcoholism (Oxford, Oxfordshire), 55(6), 702-704. https://doi.org/10.1093/alcalc/agaa092

Parlapani, E., Holeva, V., Voitsidis, P., Blekas, A., Gliatas, I., Porfyri, G. N., Golemis, A., Papadopoulou, K., Dimitriadou, A., Chatzigeorgiou, A. F., Bairachtari, V., Patsiala, S., Skoupra, M., Papigkioti, K., Kafetzopoulou, C., \& Diakogiannis, I. (2020). Psychological and behavioral responses to the COVID-19 pandemic in Greece. Frontiers in Psychiatry, 11, 821. https://doi.org/10.3389/fpsyt. 2020.00821

Pavot, W., \& Diener, E. (1993). Review of the Satisfaction With Life Scale. Psychological Assessment, 5, 164-173. https://doi.org/10.1037//1040-3590.5.2.164

Rehm, J., Kilian, C., Ferreira-Borges, C., Jernigan, D., Monteiro, M., Parry, C., Sanchez, Z. M., \& Manthey, J. (2020). Alcohol use in times of the COVID 19: Implications for monitoring and policy. Drug and Alcohol Review, 39(4), 301-304. https://doi.org/10.1111/dar.13074

Rokach, A., \& Shaked, A. (2013). Psychology of emotions, motivations, and actions. Together and lonely: Loneliness in intimate relationships-Causes and coping. Nova Science Publishers.

Rona, R. J., Fear, N. T., Hull, L., Greenberg, N., Earnshaw, M., Hotopf, M., \& Wessely, S. (2007). Mental health consequences of overstretch in the UK armed forces: First phase of a cohort study. BMJ (Clinical Research Edition), 335(7620), 603. https://doi.org/10.1136/bmj.39274.585752.BE

Rossi, R., Socci, V., Talevi, D., Mensi, S., Niolu, C., Pacitti, F., Di Marco, A., Rossi, A., Siracusano, A., \& Di Lorenzo, G. (2020). COVID-19 pandemic and lockdown measures impact on mental health among the general population in Italy. Frontiers in Psychiatry, 11, 790. https://doi.org/10.3389/ fpsyt. 2020.00790

Rubin, G. J., \& Wessely, S. (2020). The psychological effects of quarantining a city. BMJ (Clinical Research Edition), 368, m313. https://doi.org/10.1136/bmj.m313

Skapinakis, P., Bellos, S., Oikonomou, A., Dimitriadis, G., Gkikas, P., Perdikari, E., \& Mavreas, V. (2020). Depression and its relationship with coping strategies and illness perceptions during the COVID-19 lockdown in Greece: A cross-sectional survey of the population. Depression Research and Treatment, 1-11.https://doi.org/10.1155/2020/3158954

Struk, A. A., Scholer, A. A., Danckert, J., \& Seli, P. (2020). Rich environments, dull experiences: How environment can exacerbate the effect of constraint on the experience of boredom. Cognition \& Emotion, 34(7), 1517-1523. https://doi.org/10.1080/02699931.2020.1763919

Tartaglia, S., \& Bergagna, E. (2020). Alcohol consumption as a maladaptive coping strategy to face low life satisfaction. Drugs: Education Prevention and Policy, 27, 306-311. https://doi.org/10.1080/ 09687637.2019.1685938

Tsipropoulou, V., Nikopoulou, V. A., Holeva, V., Nasika, Z., Diakogiannis, I., Sakka, S., Kostikidou, S., Varvara, C., Spyridopoulou, E., \& Parlapani, E. (2020). Psychometric properties of the Greek version of FCV-19S. International journal of mental health and addiction, 1-10. Advance online publication. https://doi.org/10.1007/s11469-020-00319-8

Yeung, D.Y.-L., \& Fung, H. H. (2007). Age differences in coping and emotional responses toward SARS: A longitudinal study of Hong Kong Chinese. Aging \& Mental Health, 11(5), 579-587. https://doi. org/10.1080/13607860601086355

Veenstra, M. Y., Lemmens, P. H., Friesema, I. H., Tan, F. E., Garretsen, H. F., Knottnerus, J. A., \& Zwietering, P. J. (2007). Coping style mediates impact of stress on alcohol use: A prospective populationbased study. Addiction (Abingdon, England), 102(12), 1890-1898. https://doi.org/10.1111/j.13600443.2007.02026.x 